\title{
Does Glucagon Play a Role in the Insulin Resistance of Patients with Adult Non-Ketotic Diabetes?
}

\author{
J. M. Olefsky ${ }^{1}$, M. A. Sperling ${ }^{2}$, and G. M. Reaven ${ }^{3}$ \\ Department of Medicine, Stanford University School of Medicine, Stanford, California, \\ and UCLA Medical School, Harbor General Hospital, Torrana, California, USA
}

\begin{abstract}
Summary. Using a constant intravenous infusion technique we have measured in vivo insulin resistance in 17 normal subjects, five patients with chemical diabetes, and 13 non-ketotic diabetic patients with fasting hyperglycaemia (FBS $>120 \mathrm{mg} /$ $100 \mathrm{ml})$. All of the diabetic patients were non-obese. The results demonstrated that the diabetic patients were insulin resistant compared to normals and that the degree of insulin resistance was greater the more severe the diabetes. No differences in plasma glucagon levels were found among the different groups during the infusion studies. These results demonstrate that non-obese, non-ketotic diabetic patients are insulin resistant and that abnormalities in plasma glucagon concentrations do not account for this insulin resistance.
\end{abstract}

Key words: Insulin resistance, diabetes, glucagon, insulin, glucagon secretion.

We have previously demonstrated that insulin resistance is a characteristic feature of patients with mild glucose intolerance (chemical diabetes) and of nonketotic diabetic patients with fasting hyperglycaemia [1-3]. Insulin resistance was assessed by an infusion technique in which patients receive a constant intravenous dose of adrenaline, propranolol, glucose, and insulin for $150 \mathrm{~min} \mathrm{[1].} \mathrm{The} \mathrm{adrenaline} \mathrm{and}$

\footnotetext{
1 Dr. Olefsky is a Clinical Investigator with the Veterans Administration

2 Dr. Sperling is a recipient of a Research Career Development Award from the U.S. P. H. S., 1K04-HD 00029

3 Dr. Reaven is a Medical Investigator with the Veterans Administration
}

propranolol suppress endogenous insulin secretion and steady state plasma levels of glucose and exogenous insulin are reached by $90 \mathrm{~min}$. Each patient receives comparable amounts of insulin and glucose and similar steady state levels of exogenous insulin are achieved in all subjects. Thus, the height of the steady state plasma glucose level is a measure of each subject's ability to dispose of a comparable glucose load under the same insulin stimulus, i. e., his degree of insulin resistance. Although we have used this technique to show that non-ketotic diabetic patients are insulin resistant (i. e. high steady state plasma glucose levels), the mechanism of this abnormality is unknown. It has been suggested that hyperglucagonaemia may play an important role in the pathogenesis of the hyperglycaemia of diabetes [4] and the presence of elevated plasma glucagon levels in the diabetic patients during the infusion studies could account for the higher steady state plasma glucose levels seen in these subjects. Therefore, we have measured plasma glucagon concentrations during infusion studies in a series of normal subjects and in patients with non-ketotic diabetes.

\section{Materials and Methods}

\section{Subjects}

17 normal subjects, 5 patients with chemical diabetes, and 13 non-ketotic diabetic patients with significant fasting hyperglycaemia ( $>120 \mathrm{mg}$ ) $100 \mathrm{ml}$ ) were studied. Chemical diabetes was diagnosed if the one hour plasma glucose level exceeded $185 \mathrm{ml} / 100 \mathrm{ml}$ and the two hour level exceeded $140 \mathrm{mg} / 100 \mathrm{ml}$ following the oral ingestion of glucose $\left(40 \mathrm{gm} / \mathrm{M}^{2}\right)$ [5]. Other than diabetes, no subject had any disease or was ingesting any drug 
Table 1. Clinical Characteristics ${ }^{\mathrm{a}}$

\begin{tabular}{|c|c|c|c|c|c|}
\hline Patient Group & $\mathrm{N}$ & Age & $\begin{array}{l}\text { Relative } \\
\text { Weight }^{\text {b }}\end{array}$ & 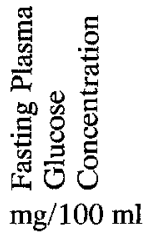 & 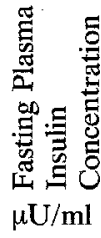 \\
\hline Normal & 17 & $\begin{array}{cc}43 & 4 \\
30-56\end{array}$ & $\begin{array}{l}0.92 \pm 0.03 \\
0.71-1.17\end{array}$ & $\begin{array}{l}87 \pm 2 \\
75-100\end{array}$ & $\begin{array}{r}12 \pm 1 \\
4-16\end{array}$ \\
\hline $\begin{array}{l}\text { Chemical } \\
\text { Diabetes }\end{array}$ & 5 & $\begin{array}{l}46 \pm 4 \\
33-39\end{array}$ & $\begin{array}{l}0.98 \pm 0.05 \\
0.81-1.10\end{array}$ & $\begin{array}{l}98 \pm 4 \\
89-112\end{array}$ & $\begin{array}{l}17 \pm 2 \\
12-21\end{array}$ \\
\hline $\begin{array}{l}\text { Fasting } \\
\text { Hyperglycaemia }\end{array}$ & 13 & $\begin{array}{l}49 \pm 3 \\
36-57\end{array}$ & $\begin{array}{l}1.00 \pm 0.05 \\
0.81-1.12\end{array}$ & $\begin{array}{l}222 \pm 24 \\
123-353\end{array}$ & $\begin{array}{l}17 \pm 2 \\
10-26\end{array}$ \\
\hline
\end{tabular}

${ }^{a}$ Numbers on the first line represent mean $\pm \mathrm{SE}$ with ranges given on the line below

b Relative weight is based on the Metropolitan Life Table

known to affect carbohydrate metabolism: none of the diabetic patients was receiving anti-diabetic medication.

\section{Measurement of Degree of Insulin Resistance}

Insulin resistance was estimated by a previously reported infusion technique [1] in which crystalline pork insulin $(80 \mathrm{mU} / \mathrm{min})$, glucose $(6 \mathrm{mg} / \mathrm{kg} / \mathrm{min})$, adrenaline $(6 \mu \mathrm{g} / \mathrm{min})$, and propranolol $(0.08 \mathrm{mg} /$ $\mathrm{min}$ ) are constantly infused intravenously via a Harvard pump over a period of $150 \mathrm{~min}$. Steady state plasma concentrations of insulin and glucose are achieved within $90 \mathrm{~min}$ of the start of the infusion, and the concentrations of plasma insulin and glucose are then measured every $10 \mathrm{~min}$ for an additional $60 \mathrm{~min}$. The degree of insulin resistance is expressed as the mean of the 7 steady state glucose levels. This approach is based upon the ability of adrenaline and propranolol to suppress endogenous insulin secretion, which has been confirmed by finding no rise in plasma endogenous insulin levels during extreme hyperglycaemia after an infusion of glucose, adrenaline and propranolol [1]. Since comparable steady state plasma levels of exogenous insulin are achieved in all subjects this technique allows us to compare the ability of different subjects to dispose of identical glucose loads under the same insulin stimulus. Therefore, the mean of the plasma glucose concentration at the steady state (SSPG level) is a direct reflection of each subject's relative degree of insulin resistance. The coefficient of variation of the steady state plasma glucose levels in individual subjects ranged from $4-14 \%$, with an average of $8 \%$ when the data from all subjects was combined. The coefficient of variation of the steady state plasma in- sulin levels ranged from $5-16 \%$ with an average of $10 \%$.

\section{Analytical Methods}

Plasma insulin concentration was determined according to the method of Desbuquois and Aurbach [6], and plasma glucose level was measured by the glucose oxidase method with a Beckman glucose analyzer (Beckman Instruments, Inc., Fullerton, Calif.). Plasma was obtained every $10 \mathrm{~min}$ during the steady state of the infusion study for measurement of plasma glucagon. Plasma glucagon was determined in duplicate by radioimmunoassay using antibody G1-5, which is highly specific for pancreatic glucagon [7]. Each sample was collected in aprotinin (Trasylol), 500 kallikrein inactivator units/ $\mathrm{ml}$, and was stored at $-20^{\circ} \mathrm{C}$ for $1-5$ months prior to assay. All samples were measured during a single assay on unextracted plasma. The coefficient of variation for five recent consecutive assay runs was $13 \%$ and $7 \%$ at a glucagon content of approximately $30 \mathrm{pg}$ and $150 \mathrm{pg}$, respectively, per sample. The limit of sensitivity is $25 \mathrm{pg} / \mathrm{ml}$ at the $95 \%$ confidence level [7].

\section{Statistical Analysis}

When different groups of patients are compared, the data are analyzed by a non-paired $t$ test. The paired $t$ test was used when the results from the same group of patients were compared under different conditions.

\section{Results}

Figure 1 summarizes the mean ( \pm SE) steady state plasma insulin and glucose levels among the 17 normal subjects, five patients with chemical diabetes, and 13 diabetic patients with fasting hyperglycaemia. It can be seen that the steady state plasma insulin levels are similar in all groups, whereas the SSPG levels progressively increase as the severity of the diabetes worsens. Thus, diabetic patients are insulin resistant compared to normal subjects.

Fasting and steady state plasma glucagon levels during the infusion studies are presented in Figure 2. It is apparent that plasma glucagon concentrations are not higher in diabetic patients as compared to normal subjects: this is true in both the basal state and during the infusion. Thus, plasma glucagon levels are not higher in the diabetic subjects and cannot account for the insulin resistance demonstrated in Figure 1. Furthermore, no significant cor- 


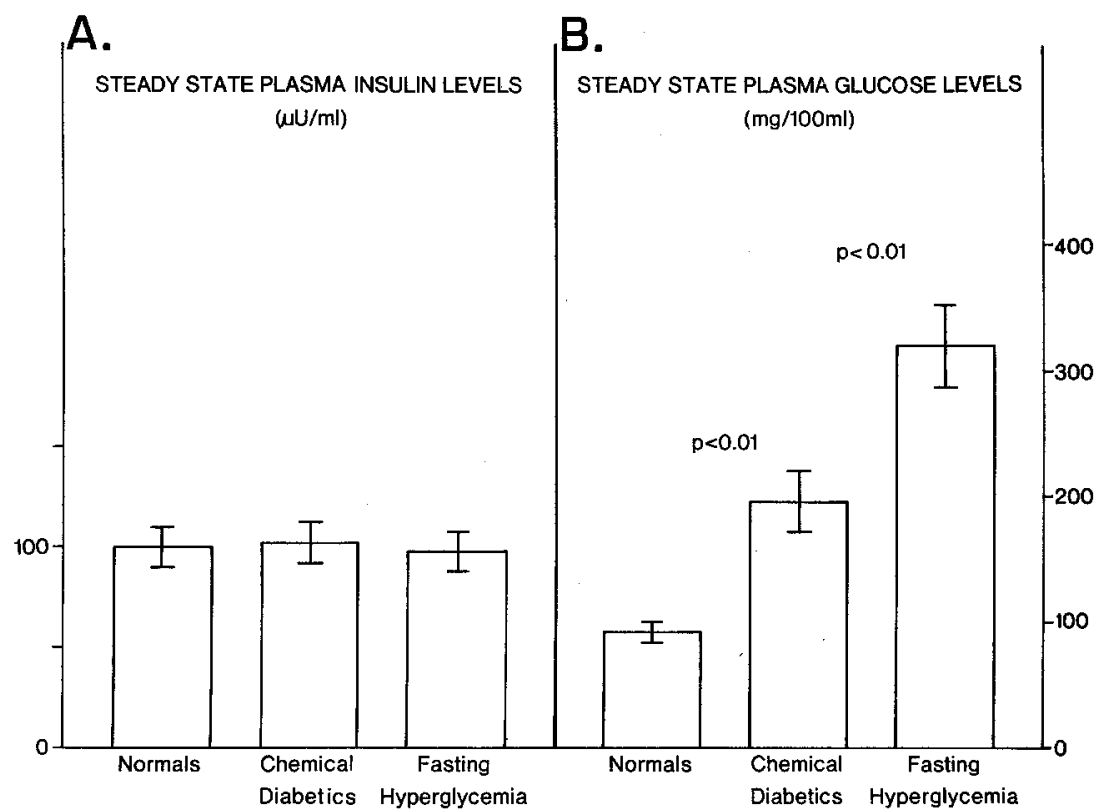

Fig. 1. Mean ( \pm SE) steady state plasma insulin (A) and glucose (B) levels during the constant intravenous study (see methods) in 17 normal subjects, 5 patients with chemical diabetes, and 13 diabetic patients with fasting hyperglycaemia relation was found between the fasting plasma glucagon level and the fasting plasma glucose level among all three groups ( $r=0.07$, NS) or between the SSPG level and the steady state glucagon level during the infusion $(\mathrm{r}=0.07, \mathrm{NS})$. Lastly, although the mean steady state plasma glucagon values are slightly less than the mean basal value in each group (Fig. 2), these differences are not significantly different either by the paired or nonpaired $t$ test.

\section{Discussion}

These results clearly show that non-ketotic nonobese diabetic patients have higher steady state plasma glucose levels than normal subjects during the infusion study, confirming our previous reports [1-3]. This occurs despite similar plasma insulin levels: therefore, these patients are more insulin resistant than normal subjects. Since plasma glucagon concentrations are similar between the normal and diabetic groups, one cannot invoke elevated plasma glucagon levels to account for the insulin resistance. These findings are consistent with those of Sherwin et al. [8], who reported that hyperglucagonaemia did not significantly contribute to the hyperglycaemia of diabetic patients as long as adequate insulin levels were present. Furthermore, Pozefsky et al. [9] found that physiologic increments in glucagon levels were without metabolic effect in the perfused forearm of man.

The current studies indicate that elevated glucagon levels do not account for the inability of an acute infusion of insulin to lower blood glucose nor-

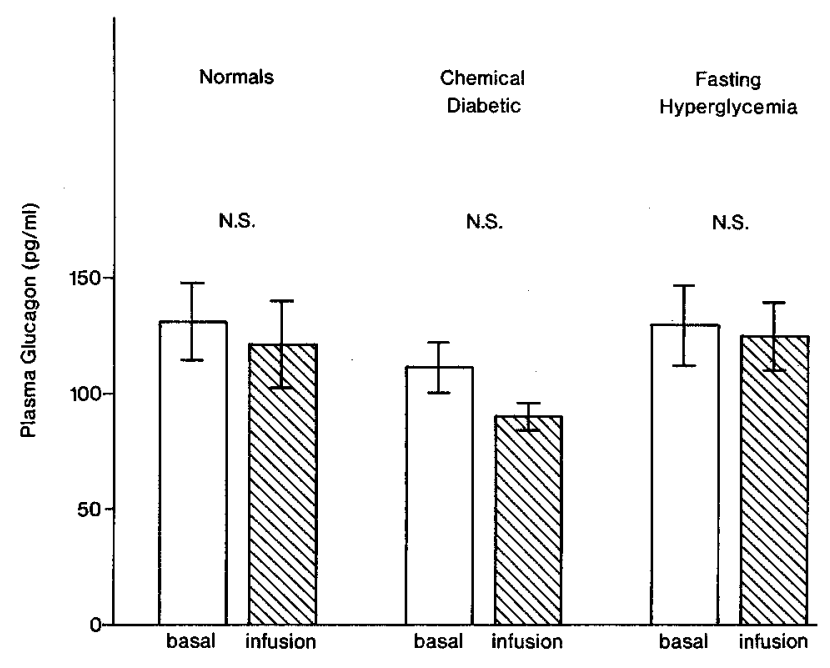

Fig. 2. Mean ( \pm SE) fasting plasma glucagon values (clear bars) and steady state plasma glucagon values (solid bars) during the infusion studies in the 3 patient groups

mally in patients with diabetes. Thus, the mechanism of this insulin resistance remains obscure. We have previously shown that a unique hyperglycaemic response to adrenaline and propranolol does not occur in diabetics, so that the elevated SSPG levels are not simply a function of the experimental infusion technique [10]. Furthermore, we have demonstrated that these elevated SSPG levels are not related to the previously expanded plasma glucose pool of patients with fasting hyperglycaemia [2], or due to saturation of the glucose uptake mechanisms [10]. Therefore, we believe that the elevated SSPG levels seen in these patients represent true insulin resistance. This insulin resistance could be due to secre- 
tion of an abnormal insulin molecule, circulating insulin antagonists, or cellular unresponsiveness to insulin's effects. Since these patients have elevated SSPG levels despite achieving the same circulating levels of exogenous insulin, an abnormal endogenous insulin molecule, or an altered proinsulin: insulin ratio cannot account for the insulin resistance. The results of the present studies demonstrate that elevated circulating levels of glucagon also do not account for this insulin resistant state, and, based on current evidence, we believe it unlikely that other insulin antagonists account for the insulin resistance in these patients [11]. It seems probable that the insulin resistance found in most adult patients with non-ketotic diabetes is due to an abnormality at the level of target tissue responsiveness to insulin action. This could involve abnormalities at the level of the insulin receptor [12], the glucose transport system, or intracellular glucose metabolism. Furthermore, as in the case of obesity [13], it is possible that multiple defects may exist and that different abnormalities are present in patients with different types of diabetes. Indeed, it seems possible that in some patients this cellular abnormality might be a primary defect, whereas in other situations it might be secondary to the chronic diabetic state.

Finally, some comment must be directed to the fact that plasma glucagon levels did not change significantly in any patient group during the infusion. It was initially claimed that glucagon levels fell during an insulin and glucose infusion in normal subjects, but not in patients with diabetes [4]. More recent experiments suggest that this is not the case, and that plasma glucagon levels fall in both groups during a glucose and insulin infusion [14]. Consequently, a decrease in the concentration of plasma glucagon might have been expected in all the study groups. On the other hand, adrenaline and propranolol were also present in the infusion mixture and it is possible that these agents offset the potential suppressive effect of the insulin and glucose.

Acknowledgement. This work was supported by the Medical Research Service of the Veterans Administration and by grants from the National Institutes of Health, HL08506 and RR 76.

\section{References}

1. Shen, S. W., Reaven, G.M., Farquhar, J. W.: Comparison of impedance to insulin-mediated glucose uptake in normal subjects and in subjects with latent diabetes. J. Clin. Invest. 49, 2151-2160 (1970)

2. Ginsberg, H., Olefsky, J.M., Reaven, G.M.: Further evidence that insulin resistance exists in patients with chemical diabetes. Diabetes 23, 674-678 (1974)

3. Ginsberg, H., Kimmerling, G., Olefsky, J.M., Reaven, G. M.: Demonstration of insulin resistance in untreated adult onset diabetic subjects with fasting hyperglycemia. J. Clin. Invest. 55, 454-461 (1975)

4. Unger, R.H.: Glucagon physiology and pathophysiology, N. Engl. J. Med. 285, 443-449 (1971)

5. Committee on Statistics of the American Diabetes Association: Standardization of the oral glucose tolerance test. Diabetes 18, 299-310 (1969)

6. Desbuquois, B., Aurbach, G.D.: Use of polyethylene glycol to separate free and antibody bound peptide hormones in radioimmunoassay. J. Clin. Endocrinol. Metab. 33, 732-738 (1971)

7. Sperling, M.A., Delamater, P.V., Kazenelson, M., Fisher, R.H., Fisher, D. A.: Development and application of a radioimmunoassay for plasma glucagon. Clin. Chem. 20, 566-570 (1974)

8. Sherwin, R. S., Fisher, M., Hendler, R., Felig, P.: Hyperglucagonemia and blood glucose regulation in normal, obese and diabetic subjects. N. Engl. J. Med. 294, 455-461 (1976)

9. Pozefsky, T., Taneredis, R.G., Moxley, R. T., Dupre, T., Tobin, J. D.: Metabolism of forearm tissues in man. Studies with glucagon. Diabetes 25, 128-135 (1976)

10. Bernstein, R., Davis, B., Olefsky, J., Reaven, G.: Mechanisms of insulin resistance in patients with fasting hyperglycemia. Diabetes 25, (Suppl. 1), 328 (Abstract) (1976)

11. Reaven, G.M., Olefsky, J.M.: Role of insulin resistance in the pathogenesis of diabetes mellitus (Review). Adv. Metab. Res. (In press) (1977)

12. Olefsky, J.M., Reaven, G.M.: Decreased insulin binding to lymphocytes from diabetic patients. J. Clin. Invest. 54, 1323-1328 (1974)

13. Olefsky, J.M.: The effects of spontaneous obesity on insulin binding, glucose transport, and glucose oxidation of isolated rat adipocytes. J. Clin. Invest. 57, 842-851 (1976)

14. Raskin, P., Fugita, Y., Unger, R. H.: Effect of insulin glucose infusions on plasma glucagon levels in fasting diabetics and non-diabetics. J. Clin. Invest. 56, 1132-1138 (1975)

Received: November 19, 1976,

and in revised form: March 21, 1977

J. M. Olefsky, M. D.

Department of Medicine

Stanford University School of Medicine S-001

Stanford, CA 94305, USA 